\title{
ESTUDO DA EXTRAÇÃO E ACILAÇÃO ENZIMÁTICA DE FLAVONOIDES OBTIDOS A PARTIR DA CASCA DE Passiflora edulis
}

\author{
I. X. MARQUES ${ }^{1}$, L. R. V. SAMPAIO ${ }^{1}$, B. A. S. SILVA², J. R. SOUSA ${ }^{1}$, M. C. M. SOUZA ${ }^{2}$ \\ e L. R. B. GONÇALVES ${ }^{1}$ \\ ${ }^{1}$ Universidade Federal do Ceará, Departamento de Engenharia Química \\ ${ }^{2}$ Universidade da Integração Internacional da Lusofonia Afro-Brasileira - Instituto de \\ Engenharias e Desenvolvimento Sustentável \\ E-mail para contato: julianarabelo09@gmail.com
}

\begin{abstract}
RESUMO - Oxidantes e radicais livres estão ligados a diversas doenças degenerativas humanas e envelhecimento celular. De modo que a aplicação de flavonoides, antioxidantes naturais, torna-se bastante atrativa, pois exibem também atividade anti-inflamatória, antitumoral e antibacteriana. Uma vez que possuem baixa lipossolubilidade, faz-se necessário a utilização de técnicas de esterificação por lipase para melhorar esta característica. Desta forma, foram avaliadas duas técnicas de extração de flavonoides a partir da casca do maracujáamarelo (Passiflora edulis), variando-se o tempo de extração e a razão sólidolíquido. A reação de esterificação foi testada em um sistema reacional modelo utilizando a rutina monohidradata comercial e lipase de Candida antartica tipo B (CALB) imobilizada em resina acrílica, com ácido esteárico. Determinou-se o teor de flavonoides por Cromatografia Líquida de Alta Eficiência (CLAE) com emprego de detector UV/PDA. Com a técnica de extração por ultrassom obteve-se um teor de flavonoides totais de $0,90 \mathrm{mg} / \mathrm{g}$ casca seca, expresso em termos de isoorientina. O sistema reacional com a rutina mostrou que houve formação de produto com e sem controle de água durante a reação.
\end{abstract}

\section{INTRODUÇÃO}

Flavonoides são compostos polifenólicos encontrados em uma vasta gama de espécies vegetais, possuindo várias funções no desenvolvimento e defesa destes organismos (Dixon e Harrison, 1990), sendo bastante diversificados, existindo mais de 8.000 tipos de flavonoides identificados (Pietta, 2000). Estes compostos apresentam efeito antioxidante (Spencer et al. 2008), vasodilatador, anti-inflamatório, antitumoral, antibacteriano e antiviral (Bendini et al., 2006). Uma grande quantidade dos flavonoides isovitexina e isoorientina pode ser encontrada na espécie Passiflora edulis (Família Passifloraceae), popularmente conhecido como maracujá amarelo e maracujá-azedo (Rudnicki et al., 2007). No Brasil em 2012 foram produzidas cerca de 776,1 mil toneladas de maracujá, concentrando-se principalmente nos estados da Bahia, Ceará, Minas Gerais e Espírito Santo (EMBRAPA).

Devido à baixa lipossolubilidade os flavonoides possuem pouca capacidade de atravessar camadas celulares e consequentemente têm sua distribuição tecidual em organismos vivos reduzida, sendo assim eliminados muito facilmente. Sua baixa 
hidrofobicidade também dificulta aplicações em certas formulações farmacêuticas e produtos alimentícios (Passicos et al., 2004; Wang et al., 2010). Desta forma, a funcionalização destes compostos com cadeias alifáticas a partir de esterificação enzimática é uma alternativa para alterar sua solubilidade em meios orgânicos.

A extração destes compostos fenólicos é uma das etapas mais importantes para o isolamento e identificação, tendo assim atraído estudos no desenvolvimento de processos e no aumento do rendimento das extrações (Pinelo et al., 2005). Métodos tradicionais de extração por uso de solventes (sólido-sólido, sólido-líquido) e não tradicionais (extração com fluido supercrítico, extração por ultrassom, extração mecânico-química, extração por microondas, extração com infravermelho e líquido pressurizado) (Chua, 2013, Xie et al., 2011, Liu et al., 2014). Independente da técnica, a extração consiste nas etapas de tumefação da matéria-prima e transferência de massa para o solvente, sendo que as variáveis de principal influência no processo são temperatura, razão sólido-líquido, tempo de extração, número de ciclos, concentração e tipo de solvente (Liu et al. 2014; Xie et al., 2011).

Assim, este trabalho tem como objetivo avaliar a quantidade de flavonoides obtidos pelos métodos de extração sólido-líquido a partir da casca da espécie $P$. edulis e o estabelecimento de um sistema reacional modelo utilizando rutina e CALB imobilizada em resina acrílica.

\section{MATERIAL E MÉTODOS}

\subsection{Matéria-prima}

Utilizou-se como matéria prima a casca da espécie Passiflora edulis seca e pulverizada adquirida comercialmente.

\subsection{Determinação do perfil cromatográfico e quantificação de flavonoides glicosilados do extrato}

As análises foram conduzidas em cromatógrafo Thermo Fisher Scientific acoplado a um detector UV/PAD. Utilizou-se coluna Lichrospher RP-18 (250mm x $4 \mathrm{~mm} ; 5 \mu \mathrm{m})$ e fase móvel composta por acetonitrila/água (1:4). O volume de injeção foi de $20 \mu \mathrm{L}$ e comprimento de onda de $340 \mathrm{~nm}$. Os flavonoides padrões isoorientina e isovitexina foram fornecidos pela Sigma, grau HPLC (98\%).

\subsection{Técnicas de extração}

Avaliaram-se duas técnicas de extração: ultrassônica e Soxhlet. Em ambas se utilizou solução de etanol 60 \% (v/v) como solvente e razão sólido-líquido $20 \mathrm{ml} / \mathrm{g}$ de casca seca. As condições de operação foram obtidas a partir da literatura (Ciric et al., 2012; Liu et al., 2014). $\mathrm{O}$ extrato obtido de cada tipo de extração foi então diluído para $100 \mathrm{ml}$ e armazenado sob refrigeração para posterior análise.

$\mathrm{Na}$ extração Soxhlet utilizou-se a razão $20 \mathrm{ml}$ de solvente/g de casca, sendo conduzida a $60^{\circ} \mathrm{C}$. Variou-se o tempo de extração em 2 horas em ciclo único e 4 horas divididas em 2 
ciclos. Ao fim do ciclo as amostras foram centrifugadas a $6000 \mathrm{rpm}$, por 5 minutos a $10^{\circ} \mathrm{C}$. A extração por ultrassom foi realizada em sonicador Ultra Cleaner Modelo 1450A. A operação foi conduzida a $25^{\circ} \mathrm{C}$ durante 2 horas divididas em 4 ciclos de 0,5 hora. Ao fim de cada ciclo as amostras foram centrifugadas a $6000 \mathrm{rpm}$, por 5 minutos a $10^{\circ} \mathrm{C}$.

\subsection{Acilação enzimática de flavonoides}

Devido à dificuldade de solubilização do extrato liofilizado elaborou-se um sistema modelo de reação utilizando rutina como flavonoide glicosilado. Seguiu-se a metodologia proposta por Zheng et al. (2013) com modificações. A reação foi conduzida em tubos de ensaio com tampa incubados em agitador rotativo a $200 \mathrm{rpm}$ durante 72 horas a $50{ }^{\circ} \mathrm{C}$. A concentração inicial de rutina foi de $1 \mathrm{~g} / \mathrm{L}$ e utilizou-se como solvente a solução álcool tercamílico/acetona 2:1 (v/v). Utilizou-se ácido oleico como doador acil em uma razão $10 \mathrm{~mol}$ de ác. oleico/mol de rutina. Adicionou-se a CALB imobilizada em resina acrílica (Novozym 435) na concentração de $20 \mathrm{~g} / \mathrm{L}$. As reações foram conduzidas com e sem peneira molecular (zeólita $3 \AA$ ) com objetivo de avaliar a influência do teor de água durante a reação. O solvente e o ácido oleico foram previamente secos com zeólita $3 \AA$ na concentração $100 \mathrm{~g} / \mathrm{L}$. A quantificação do éster de rutina, expresso em termos de rutina, foi realizada por CLAE.

\subsection{Determinação do perfil cromatográfico dos constituintes da reação em um sistema modelo}

As análises foram conduzidas em cromatógrafo Waters acoplado a detector UV e controlado pelo software Breeze. Utilizou-se coluna Lichrospher RP-18 (250mm x $4 \mathrm{~mm}$; $5 \mu \mathrm{m})$ fornecida pela Merck para separação e quantificação, com gradiente de eluição de metanol e solução de ácido acético $3 \%(\mathrm{v} / \mathrm{v})$ em fluxo de $0,8 \mathrm{~mL} / \mathrm{min}: 0,8 \mathrm{~mL} / \mathrm{min}$ : $0 \mathrm{~min}$ (30/70), $5 \mathrm{~min}(100 / 0), 10 \mathrm{~min}(100 / 0), 15 \mathrm{~min}(30 / 70), 20 \mathrm{~min}(30 / 70)$ (Ardhaoui et al., 2004). As amostras foram injetadas automaticamente $(20 \mu)$ e monitorada a $280 \mathrm{~nm}$. A curva de calibração foi construída utilizando-se rutina grau HPLC (Sigma) com concentrações entre 5 e $40 \mathrm{mgL}$.

\section{RESULTADOS}

\subsection{Análise das técnicas de extração de flavonoides da casca de $\boldsymbol{P}$. edulis}

O teor de flavonoides totais obtidos por cada técnica, e suas condições, foram exibidas na Tabela 1.

Tabela 1 - Teor de flavonoides totais obtidos pelos diferentes métodos de extração

\begin{tabular}{lccccc}
\hline Técnica & $\begin{array}{c}\text { Temperat } \\
\text { ura } \\
\left({ }^{\mathbf{0}} \mathbf{C}\right)\end{array}$ & $\begin{array}{c}\text { Razão } \\
\text { sólido/líquido } \\
(\mathbf{g} / \mathbf{m l})\end{array}$ & $\begin{array}{c}\text { Tempo de } \\
\text { extração } \\
(\mathbf{h})\end{array}$ & $\begin{array}{c}\mathbf{N}^{\mathbf{0}} \mathbf{d e} \\
\text { Ciclo } \\
\mathbf{s}\end{array}$ & $\begin{array}{c}\text { Teor (mg de } \\
\text { isoorientina } \\
\text { /g de casca seca) }\end{array}$ \\
\hline Ultrassom & 25 & $1 / 20$ & 2 & 4 & 0,90 \\
Soxhlet & 60 & $1 / 20$ & 4 & 2 & 0,27 \\
Soxhlet & 60 & $1 / 20$ & 2 & 1 & 0,16 \\
\hline
\end{tabular}


Pelos dados apresentados na Tabela 1, o método de extração por ultrassom apresentou um teor máximo de flavonoides expressos em isoorientina de $0,90 \mathrm{mg} / \mathrm{g}$ de casca seca, valor 3,3 vezes maior que o resultado da extração Soxhlet com dois ciclos de $2 \mathrm{~h}$. Este estudo tem grande relevância para as futuras etapas de isolamento da isoorientina e isovitexina.

\subsection{Sistema modelo de acilação enzimática com rutina}

Os sistemas foram avaliados em duas condições: com e sem controle de água durante a reação através da adição de zeólita $3 \AA$ ao meio reacional. As reações foram monitoradas através de cromatografia líquida nos tempos de 0,24, 48 e $72 \mathrm{~h}$.

Os cromatogramas do meio reacional estão apresentados nas Figuras 1 e 2. Observouse, nos dois sistemas avaliados, a presença de um pico em 8,7 min após $24 \mathrm{~h}$ de reação que se manteve ao longo das 72 horas de reação. Dada à possibilidade da formação de subprodutos, além da água, durante a esterificação direta dos flavonoides será realizada a caracterização químico-estrutural do produto obtido através de técnicas espectroscópicas, como espectrometria de massa e ressonância magnética nuclear.

Figura 1 - Cromatograma do meio reacional na ausência de zeólita em $\mathrm{t}=0 \mathrm{~h}$.

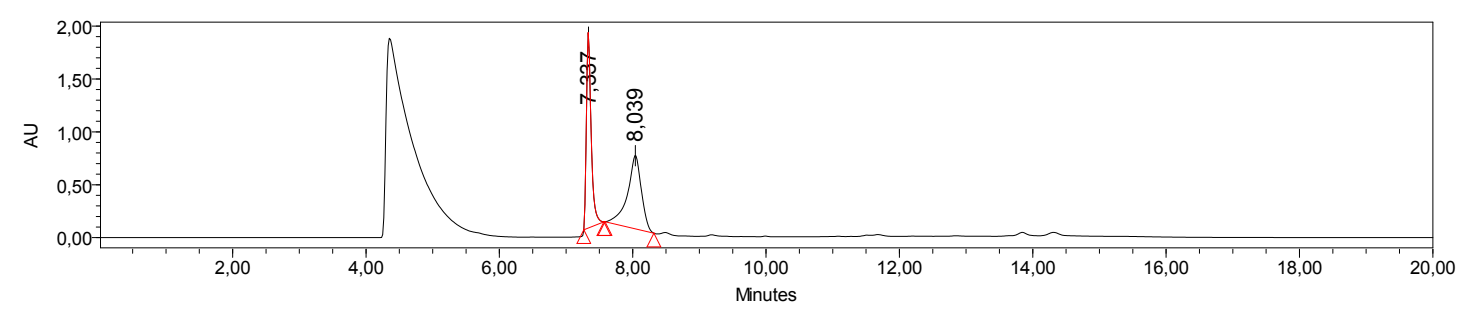

Figura 2 - Cromatograma do meio reacional na ausência de zeólita em $\mathrm{t}=72 \mathrm{~h}$.

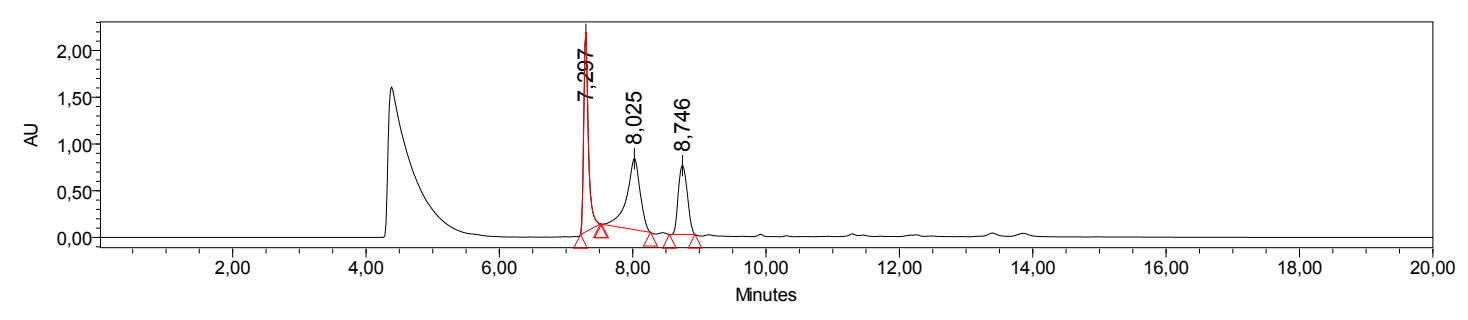

\section{CONCLUSÕES}

A casca de $P$. edulis (maracujá amarelo) constitui uma fonte promissora de flavonoides. Dentre as técnicas de extração estudadas, a extração com ultrassom forneceu o melhor rendimento, equivalente a $0,90 \mathrm{mg} / \mathrm{g}$ de casca seca. O sistema reacional estudado com a rutina mostrou que houve a formação de produto, com e sem controle do teor de água durante a reação. Este será, posteriormente, purificado e caracterizado por técnicas espectroscópicas.

\section{REFERÊNCIAS}


ARDHAOUI, M.; FALCIMAIGNE, A.; OGNIER, S.; ENGASSER, J.M; MOUSSOU, P.; PAULY, G.; GHOUL, M. Effect of acyl donor chain length and substitutions pattern on the enzymatic acylation of flavonoids, Journal of Biotechnology, v. 110, n. 3, p. $265-$ $271,2004$.

BENDINI, A.; CERRETANI, L.; PIZZOLANTE, L.; TOSCHI, T. G.; GUZZO, F.; CEOLDO, S.; MARCONI, A. M.; ANDREETTA, F.; LEVI, M. Phenol content related to antioxidant and antimicrobial activities of Passiflora spp. extracts. Eur. Food Res. Technol., v.223, p. 102-109, 2006.

CHUA, L. S. A review on plant-based rutin extraction methods and its pharmacological activities, Journal of Ethnopharmacology, v. 150, p. 805-817, 2013.

CIRIC, A.; PROSEN, H.; JELIKIC-STANKOV, M.; DURDEVIC, P. Evaluation of matrix effect in determination of some bioflavonoids in foods amples by LC-MS/MS method, Talanta, v. 99, $780-790,2012$.

DIXON, R. A.; HARRISON, M. J. Activation, structure, and organization of genes involved in microbial defense in plants. Advances in Genetics, v. 28, p. 165-234, 1990.

LIU, Y.; HONGWU, W.; CAI, X. Optimization of the extraction of total flavonoids from Scutellaria baicalensis Georgius in the response surface methodology, Journal of Food Science Technology, 2014

PASSICOS, E.; SANTARELLI, X.; COULON, D. Regioselective acylation of flavonoids catalyzed by immobilized Candida antarctica lipase under reduced pressure. Biotechnol. Lett., v. 26, p. 1073-1076, 2004.

PIETTA, G. Flavonoids as antioxidants. J Nat Prod., v. 63, n. 7, p. 1035-1042, 2000.

PINELO, M.; RUBILAR, M.; JEREZ, M.; SINEIRO, J.; NUNEZ, M. J., Effect of solvent, temperature, and solvent-to-solid ratio on the total phenolic content and antiradical activity of extracts from different components of grape pomace. J. Agric. Food Chem, v. 53, p. $2111-2117,2005$.

RUDNICKI, M.; DE OLIVEIRA, M. R.; PEREIRA, T. V.; REGINATTO, F. H.; DALPIZZOL, F.; MOREIRA, J. C. F. Antioxidant and antiglycation properties of Passiflora alata and Passiflora edulis extracts. Food Chem., v. 100, 719-724, 2007.

SPENCER, J.P.; ABD EL MOHSEN, M. M.; MINIHANE, A. M.; MATHERS, J. C. Biomarkers of the intake of dietary polyphenols: strengths, limitations and application in nutrition research. British Journal of Nutrition, v. 99, n. 01, p. 12-22, 2008.

WANG, A.; ZHANG, F.; HUANG, Y.; LI, H.; WANG, Q.; ZHAOWU, Z.; XIE, T. New progress in biocatalysis and biotransformation of flavonoids. J. Med. Plant Res., v. 4, p. 847-856, 2010. 
XIE, J.; SHI, L.; ZHU, X.; WANG, P.; ZHAO, Y.; SU, W. Mechanochemical-assisted eficient extraction of rutin from Hibiscus mutabilis L., Innovative Food Science and Emerging Technologies, v. 12, p. 146-152, 2011.

ZHENG, M. M.; WANG, L.; HUANG, F. H.; GUO, P. M.; WEI, F.; DENG, Q. C.; WAN, C. Y. Ultrasound irradiation promoted lipase-catalyzed synthesis of flavonoid esters with unsaturated fatty acids. Journal of Molecular Catalysis B: Enzymatic, v. 95, p. 82-88, 2013. 